\title{
Study of Vertical Characteristics with Changes in Prepressure of Rubber Pad Used by High-Speed EMU
}

\author{
Chuanbo Xu $\mathbb{D}^{1,2}$ Mao-Ru Chi ${ }^{1},{ }^{1}$ Liangcheng Dai $\mathbb{D}^{1},{ }^{1}$ Yiping Jiang $\mathbb{D},{ }^{1}$ \\ and Zhaotuan Guo iD 1 \\ ${ }^{1}$ State Key Laboratory of Traction Power, Southwest Jiaotong University, Chengdu, China \\ ${ }^{2}$ Henan Engineering Research Center of Rail Transit Intelligent Security, Zhengzhou Railway Vocational \& Technical College, \\ Zhengzhou, China
}

Correspondence should be addressed to Mao-Ru Chi; cmr2000@163.com

Received 21 February 2020; Accepted 28 May 2020; Published 17 June 2020

Academic Editor: Dora Foti

Copyright (C) 2020 Chuanbo Xu et al. This is an open access article distributed under the Creative Commons Attribution License, which permits unrestricted use, distribution, and reproduction in any medium, provided the original work is properly cited.

Rubber spring plays an important role in improving train performance, so the study of rubber spring is one of the focuses of train dynamics. The vertical characteristic parameters of rubber spring are affected by prepressure significantly, as a result of varying parameters of static stiffness, dynamic stiffness, periodic energy consumption, damping coefficient, and so on. In order to use the theoretical method to calculate the precise static stiffness and predict the dynamic characteristics and to reduce the workload of the rubber spring performance test, this paper takes the annular rubber pad as an example to study with different prepressures. In this paper, the convexity coefficient correction formula (simply called the CCCF) for static stiffness calculation and the dynamic fiducial conversion coefficient (simply called the DFCC) method based on different prepressures are proposed. Through further analysis, the accuracy of CCCF and DFCC is proved both theoretically and experimentally. The results have shown precise prediction of the variation of prepressure on rubber spring parameters by using CCCF and DFCC and can be used as the reference of accurate vertical dynamic-static characteristics of the rubber spring.

\section{Introduction}

With the improvement of train speed rising, people are more concerned about the riding comfort, reducing noise, and increasing stability. Rubber components are being widely used in rail transit vehicles, and they play a vital role for improving the performance of the train. As a result, calculation of the performance parameters has been one of the key research areas in train dynamics. As a result, the accurate calculation of the performance parameters of rubber components has always been one of the focuses of train dynamics research.

At present, there are many research studies on the static stiffness calculation of rubber components under the condition of small deformation at room temperature [1-7]. There are many theoretical and empirical formulas for specific shapes of rubber components, and many of these formulas adopt linear stiffness or consider certain geometric nonlinearity. A finite element method is also widely used in the study of the rubber model; it can simulate the static test more accurately. Moreover, this method has great advantages for the rubber element with an irregular shape, but the parameters calculated in the computer simulation still depend on the test data. The performance of rail transit vehicles is greatly affected by the dynamic mechanical performance of rubber components. For this reason, the dynamic characteristics of rubber components have always been an important research topic, and the research focuses on the dynamic stiffness and dynamic damping. Most of the calculations of dynamic characteristics adopt different combinations of springs, dampers, friction antibodies, and fractional-order modules for the analysis, and the influencing factors mainly can be given thought to frequency and amplitude [8-16]. Sjöberg [14-16] played a very important role in the research of rubber spring combination model. Recently, the fractional-order model has been studied 
extensively and deeply, and many meaningful results have been obtained. There are many factors that affect the performance of rubber springs, such as frequency, dynamic amplitude, basic size, material, temperature, and prepressure, but there are relatively few studies on temperature and prepressure. Li et al. [17-22] studied the performance of rubber components in different temperature states and have proven that temperature has an influence on the performance of rubber. Especially in the low-temperature state, the rubber property is obviously changed, which is caused by low-temperature crystallization. Kari $[23,24]$ proposed a nonlinear temperature model of rubber pad based on shape factor and studied the influence of temperature and prepressure on material geometric parameters. The rectangular approximation method was adopted for deformation of rubber in this model. Cheng et al. [25] studied the nonlinear relationship between stiffness and prepressure of different types of rubber spring. Koh et al. [26, 27] derived the theoretical formula for calculating the vertical stiffness of vibration isolation rubber pad. Foti et al. [28] studied the dynamic characteristics of the rolling isolation device from the theoretical point of view and analyzed that its performance was affected by many factors, including the load factor. In addition, through further study, the research and calculation method are provided for the optimal design of rolling vibration isolation device [29].

As the performance of high-speed trains is more intensified with the load conditions variation, it is necessary to conduct a study of the dynamic and static performance of rubber springs under different prepressures. In this study, with annular rubber pad of the high-speed train bogie as an example, the dynamic-static performances under different prepressures were studied. Based on the study, we proposed a convexity coefficient correction formula (simply called the CCCF) for static stiffness calculation and the dynamic fiducial conversion coefficient (simply called the DFCC) method for dynamic performances calculation, and, furthermore, the theoretical rationality is proved and the conformity of the test results is analyzed. The results show that CCCF and DFCC can well calculate and describe the dynamic-static performances of annular rubber pad.

\section{Parameter Definition and Test}

2.1. Parameter Definition. Rubber spring has nonlinear dynamic-static characteristics, so some characteristic parameters have different definition methods under different research focuses and calculation conditions. In order to facilitate the research, some characteristic parameters are defined in this study.

As shown in Figure 1, the stiffness of the rubber spring is defined as

$$
k=\frac{F_{\max }-F_{\min }}{x_{\max }-x_{\min }}
$$

where $x_{\max }$ and $x_{\min }$ represent the maximum and minimum displacements and $F_{\max }$ and $F_{\min }$ represent the corresponding maximum and minimum forces; take the preloading position as the displacement point 0 , and set the

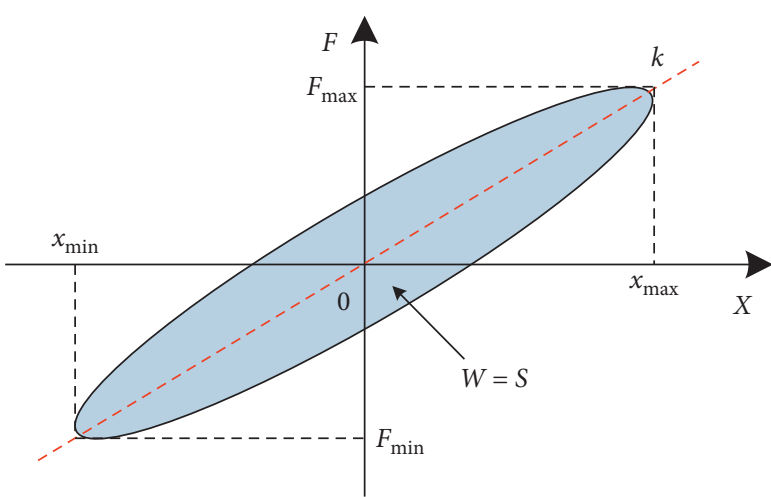

Figure 1: Force-displacement hysteresis curve of rubber spring.

corresponding force value as 0 . The equivalent damping coefficient $c$ is defined as

$$
c=\frac{W}{\pi \omega x_{0}^{2}}=\frac{S}{\pi \omega x_{0}^{2}}
$$

where $W$ is the energy dissipated during a period of vibration, $S$ is the area enclosed by the hysteresis curve, and $\omega$ and $x_{0}$ represent the angular frequency and amplitude of vibration, respectively. Loss factor $\eta$ represents the rubber spring's ability to dissipate energy in one cycle. The hysteresis curve is assumed to be a central symmetric graph with a center point of $0 ; \eta$ is defined as

$$
\eta=\frac{W}{2 k x_{0}^{2}+1 / 2 W}=\frac{S}{2 k x_{0}^{2}+1 / 2 S}=\frac{c \pi \omega x_{0}^{2}}{2 k x_{0}^{2}+1 / 2 c \pi \omega x_{0}^{2}}
$$

for the rubber spring, $2 k x_{0}^{2}+1 / 2 S$ is the maximum work done by the external force in one stable period.

With regard to the static stiffness, it is impossible to measure stiffness in an absolute static condition, so the quasistatic stiffness at extremely low frequencies is used. The static stiffness is also calculated in the same way as the dynamic stiffness, namely, formula (1). In this study, static stiffness and quasi-static stiffness are considered to be the same. Owing to the equivalent damping coefficient due to internal friction in the rubber spring, the hysteretic curve is always present no matter how low the frequency of the quasi-static test is, but the hysteretic curve is closer to the linear form.

2.2. Test Equipment and Data Processing. The annular rubber pad used for the bogie of the Standard EUM in China is selected for the test analysis. The first series rubber pad has a metal cover plate at both ends, as shown in Figure 2. The hardness is $55 \mathrm{HS}$, and Young's modulus $E$ is $2.28 \mathrm{MPa}$. Vertical dynamic and static tests were performed on the rubber pad in Figure 2 using the test equipment shown in Figure 3 . In the test, the room temperature was set to $25 \pm 2^{\circ} \mathrm{C}$, and the input was sinusoidal $x=x_{0} \sin \omega t x=x_{0} \sin \omega t$, taking preloading position as displacement $0 \mathrm{~mm}$. The static test was performed by using the quasi-static test method with a very low frequency, the frequency less than $0.005 \mathrm{~Hz}$, and a cycle lasts more than $5 \mathrm{~min}$ at quasi-static condition.

In the quasi-static conditions, the amplitudes were set as $0.2 \mathrm{~mm}, 0.5 \mathrm{~mm}, 0.7 \mathrm{~mm}, 1 \mathrm{~mm}$, and $2 \mathrm{~mm}$; the prepressures 


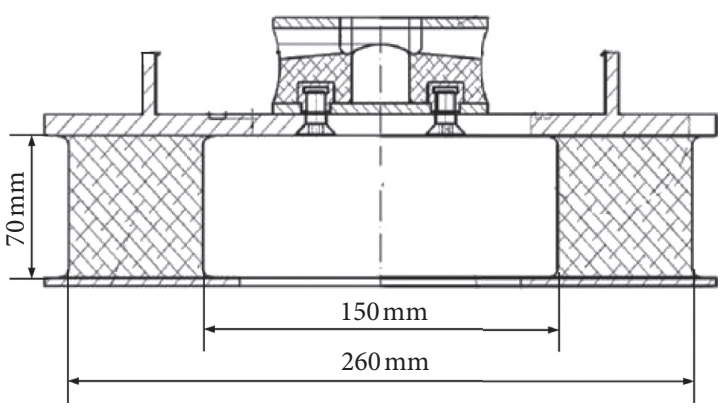

Figure 2: Rubber pad of China standard EMU.

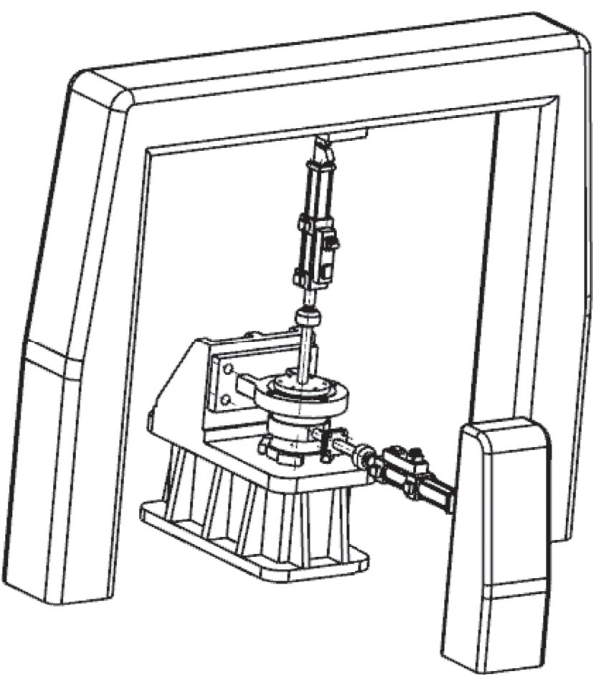

FIgUre 3: Test equipment.

were set as $45 \mathrm{kN}, 57 \mathrm{kN}, 65 \mathrm{kN}, 75 \mathrm{kN}$, and $85 \mathrm{kN}$. In the dynamic conditions, the frequencies were $0.5 \mathrm{~Hz}, 1 \mathrm{~Hz}, 2 \mathrm{~Hz}$, $5 \mathrm{~Hz}, 7 \mathrm{~Hz}$, and $10 \mathrm{~Hz}$, and the amplitude was $0.2 \mathrm{~mm}$, $0.5 \mathrm{~mm}, 1 \mathrm{~mm}, 1.5 \mathrm{~mm}$, and $2 \mathrm{~mm}$; the prepressures were $45 \mathrm{kN}, 57 \mathrm{kN}, 65 \mathrm{kN}, 75 \mathrm{kN}$, and $85 \mathrm{kN}$. Before the test, a large prepressure was applied to the rubber spring, and it vibrated for 20 cycles under the maximum excitation, and the test began $10 \mathrm{~min}$ later. In the formal test, 10 cycles were tested in each working condition, and the force-displacement data of the last 3 cycles were recorded; the interval between each working condition was $3 \mathrm{~min}$, so as to avoid affecting the analysis due to obvious stress softening.

Formula (1) was used to process the force-displacement data obtained from the test to obtain the equivalent stiffness $k$. Periodic energy consumption $W$ is the area $S$ enclosed by the force-displacement hysteretic curve, which was obtained by computer numerical integration with computer drawing software origin $2019 b$ and was calculated by arithmetic mean value for the data of three cycles tested in the same working condition. In order to facilitate comparative analysis, considering that too small measurement amplitude will lead to a large relative error of the test equipment and too large measurement amplitude will lead to significant stress softening, the static stiffness analysis in this paper takes the amplitude of $1 \mathrm{~mm}$ as the calculation standard when there is no specified amplitude (Figure 4).

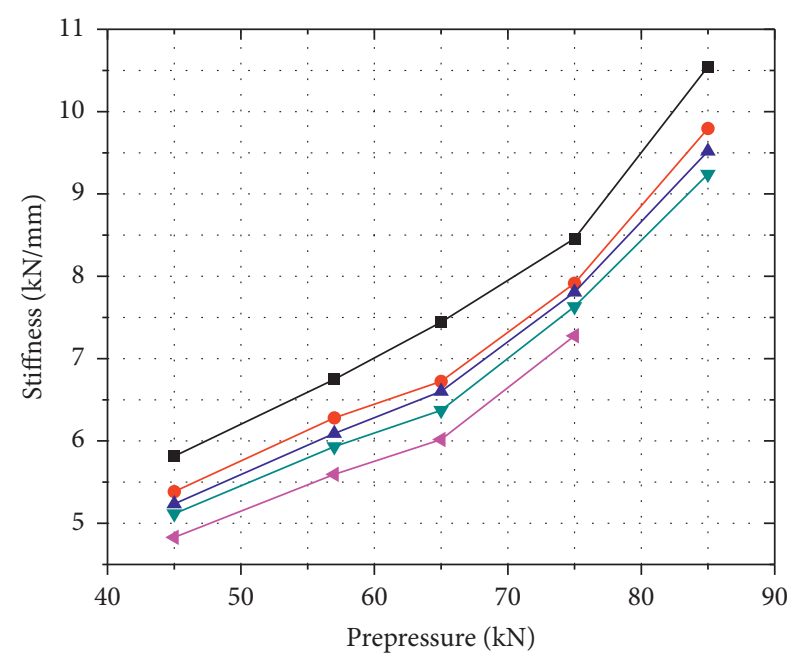

$\begin{array}{ll}\text { Amplitude of static test } & \\ \rightarrow-0.2 \mathrm{~mm} & \longrightarrow-1 \mathrm{~mm} \\ \longrightarrow 0.5 \mathrm{~mm} & -2 \mathrm{~mm} \\ \leftarrow 0.7 \mathrm{~mm} & \end{array}$

FIgURE 4: The curve of quasi-static stiffness with prepressure.

2.3. Preliminary Analyses of Test Results. When the dynamic frequency is represented by $i$ and the amplitude is represented by $j$, the dynamic stiffness and equivalent damping coefficient at different frequencies and amplitudes are represented in $k_{i j}$ and $c_{i j}$, respectively. According to formulas (1)-(3), the stiffness, equivalent damping, and loss factors are calculated. $W_{i j}$ is calculated by numerical integration of origin software. Since there are many test conditions, the calculation results of some typical conditions are selected as shown in Figure 5. Figure 5(a) shows the curve of dynamic stiffness $k_{i j}$ changing with prepressure, Figure 5(b) shows the curve of periodic energy consumption $W_{i j}$ changing with prepressure, Figure 5(c) shows the curve of equivalent damping coefficient $c_{i j}$ changing with prepressure, and Figure 5(d) shows the curve of loss factor $\eta$ changing with prepressure.

According to the analyses in Figure 5, the stiffness, cycle energy consumption, and equivalent damping coefficient of the rubber pad all increase with an increase in prepressure. For different combinations of frequency and amplitude, the dynamic parameters have similar increasing proportions with the change of prepressure. The loss factor decreases with an increase in prepressure, but the change range is not large; that is, the loss factor is less sensitive to the change of prepressure. Based on the above analyses, the prepressure has an important influence on the dynamic and static characteristics of the rubber pad; therefore, it is necessary to study these relationships quantitatively.

\section{Research on the Parameter Calculation Model Based on Prepressure Change}

According to the preliminary analyses of 2.3, the stiffness, periodic energy consumption, and equivalent damping coefficient of the rubber spring all increase with the increase of prepressure, and the increase proportions of dynamic and static parameters are also similar. Based on the above analyses, 


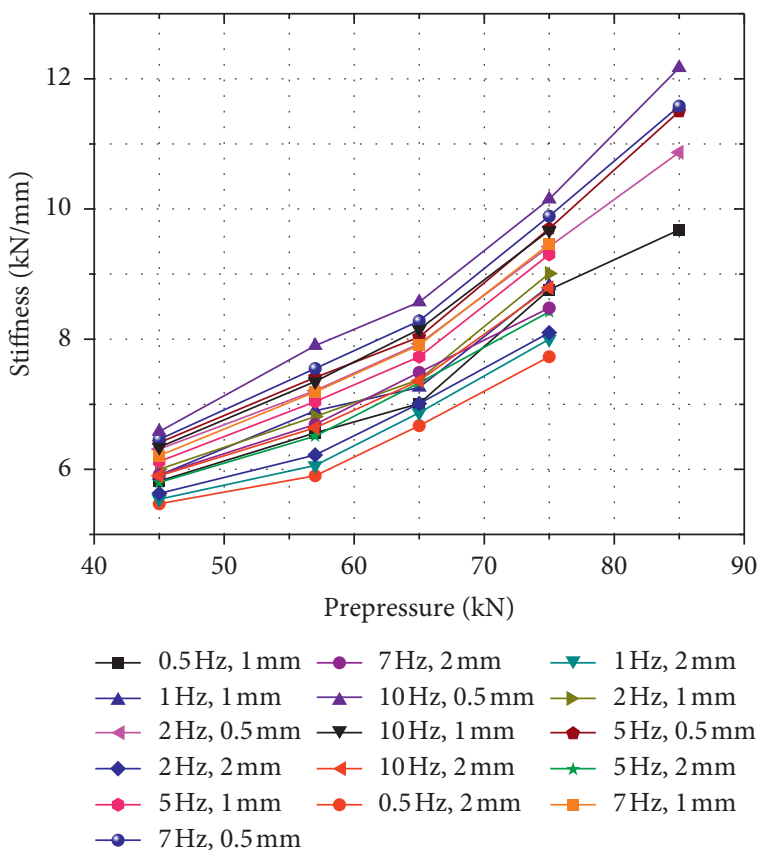

(a)

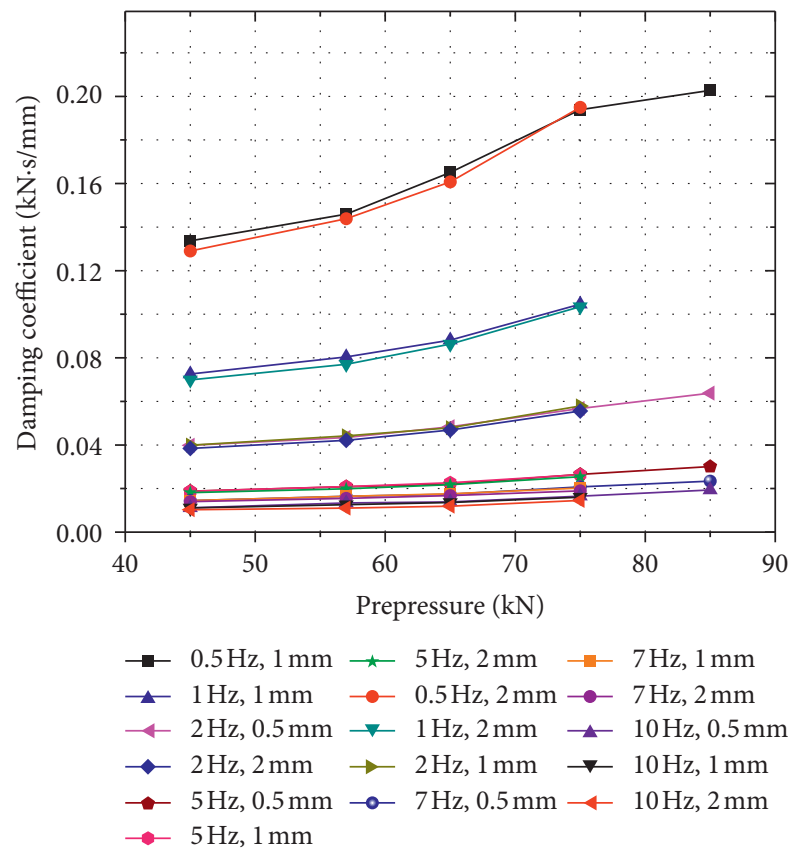

(c)

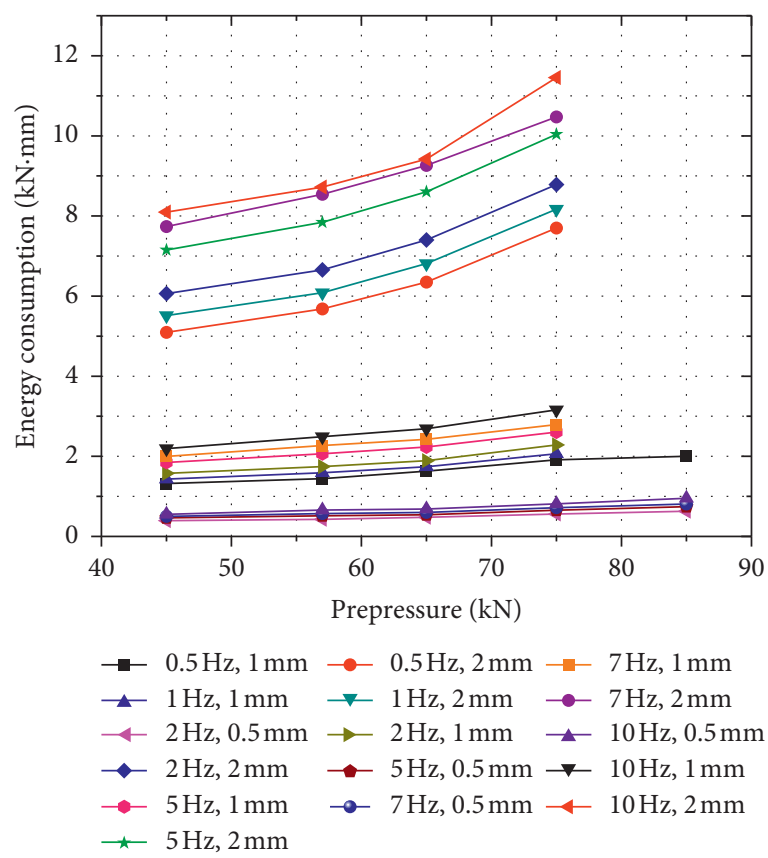

(b)

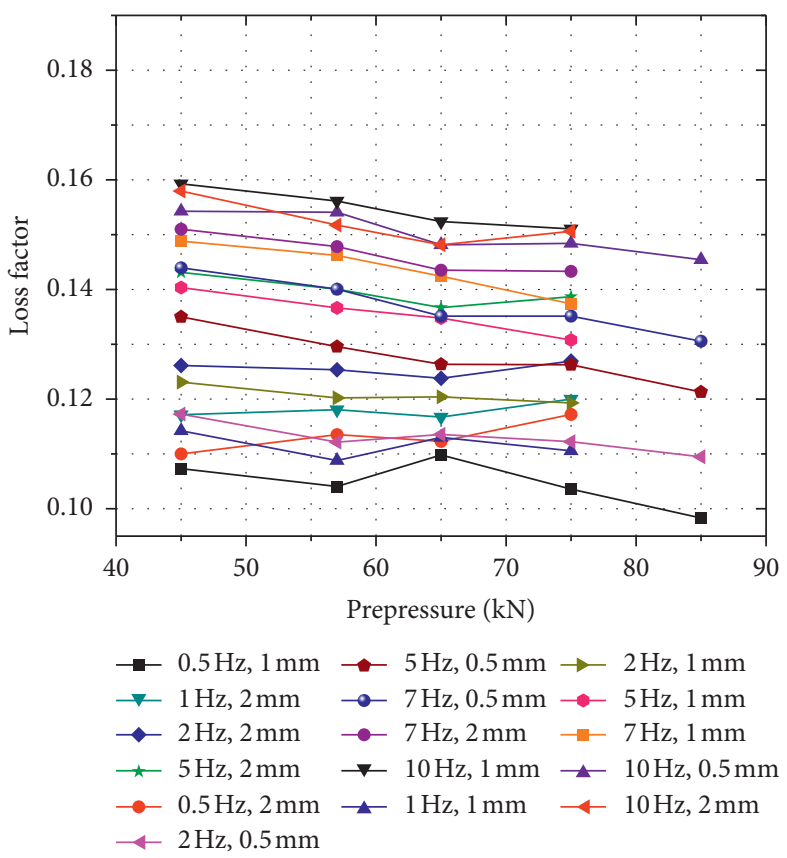

(d)

FIGURE 5: The change curve of dynamic parameters with prepressure.

we make the following assumptions: (a) Assume that the dynamic stiffness and static stiffness have the same proportion of increase with the change of prepressure. (b) Assume that the dynamic periodic energy consumption, equivalent damping coefficient, and dynamic stiffness have the same proportion of increase with the change of prepressure.

When the prepressure changes, according to the assumptions from the static stiffness change law, dynamic parameters change law can be obtained, so accurate calculation of rubber spring static stiffness is very necessary.
3.1. Static Stiffness Calculation Based on Rectangular Hypothesis. For rail vehicle bogies, annular rubber pad is a common rubber spring. In the static compression process, the actual size of the rubber pad is constantly changing, so stiffness is a function of deformation rather than a fixed value. Through a large number of tests, the relationship between static stiffness and prepressure is nonlinear. When calculating the static stiffness of rubber spring, it is generally assumed that the change of ring rubber pad is regular; that is, the vertical section of the rubber pad is rectangular, and 
further assume that the changes of inner circle radius and outer circle radius are the same, which can be expressed by the following formula:

$$
R_{1}-R=r-r_{1}=d,
$$

where $R$ is the initial outer circle radius, $r$ is the initial inner circle radius, $R_{1}$ is the outer circle radius after compression, $r_{1}$ is the inner circle radius after compression, and $d$ is the change in radius. According to the invariance of the volume, the following relation can be obtained:

$$
\begin{aligned}
\pi\left(R_{1}^{2}-r_{1}^{2}\right)\left(H-h_{\text {pre }}\right) & =\pi\left(R^{2}-r^{2}\right) H, \\
d & =\frac{1}{2}\left(\frac{(R-r) h_{\text {pre }}}{H-h_{\text {pre }}}\right), \\
R_{1} & =R+\frac{1}{2}\left(\frac{(R-r) h_{\text {pre }}}{H-h_{\text {pre }}}\right), \\
r_{1} & =r-\frac{1}{2}\left(\frac{(R-r) h_{\text {pre }}}{H-h_{\text {pre }}}\right),
\end{aligned}
$$

where $h_{\text {pre }}$ represents the precompressed amplitude and $H$ is the initial height of the rubber pad. The following calculation is performed according to the empirical formula:

$$
\begin{aligned}
S_{1}= & \frac{A_{\mathrm{c} 1}}{A_{\mathrm{f} 1}}=\frac{\pi\left(R_{1}^{2}-r_{1}^{2}\right)}{2 \pi\left(R_{1}+r_{1}\right)\left(H-h_{\mathrm{pre}}\right)}=\frac{R_{1}-r_{1}}{2\left(H-h_{\mathrm{pre}}\right)}, \\
k_{\mathrm{st} 1}= & \frac{A_{\mathrm{c} 1} \mu_{1} E}{H-h_{\mathrm{pre}}}=\frac{A_{\mathrm{c} 1}\left(1+2 S_{1}^{2}\right) E}{H-h_{\mathrm{pre}}}=\frac{\pi\left(R_{1}^{2}-r_{1}^{2}\right) E}{H-h_{\mathrm{pre}}} \\
& \cdot\left[1+\frac{\left(R_{1}-r_{1}\right)^{2}}{2\left(H-h_{\mathrm{pre}}\right)^{2}}\right],
\end{aligned}
$$

where $S_{1}$ is the area ratio, $A_{f 1}$ is the sum of the internal and external free areas, $k_{\mathrm{st1}}$ is static stiffness, $A_{\mathrm{cl}}$ is the bearing area, and $\mu_{1}$ is the vertical shape coefficient. At this point, the prepressure $F_{\text {st1 }}$ can be calculated as follows:

$$
F_{\text {st } 1}=\int_{0}^{h_{\text {pre }}} K_{\text {st } 1} \mathrm{~d} z=\int_{0}^{h_{\text {pre }}} \frac{\pi\left(R_{1}^{2}-r_{1}^{2}\right) E}{H-z}\left[1+\frac{\left(R_{1}-r_{1}\right)^{2}}{2(H-z)^{2}}\right] \mathrm{d} z .
$$

Due to the influence of the friction of the end surface, the actual bearing area after the deformation is generally less than the calculated value. In particular, the bearing area of the rubber pad with cover is still the original value, and so $A_{\mathrm{cl}}=\pi\left(R^{2}-r^{2}\right)$, but the free area is variable. In this case, formulas (6) and (7) can be modified as follows:

$$
\begin{aligned}
& k_{\text {st } 1}=\frac{A_{\mathrm{cl} 1} \mu_{1} E}{H-h_{\text {pre }}}=\frac{\pi\left(R^{2}-r^{2}\right) E}{H-h_{\text {pre }}}\left[1+\frac{(R-r)^{2}}{2\left(H-h_{\text {pre }}\right)^{2}}\right], \\
& F_{\text {st } 1}=\int_{0}^{h_{\text {pre }}} k_{\text {st } 1} \mathrm{~d} z=\int_{0}^{h_{\text {pre }}} \frac{\pi\left(R^{2}-r^{2}\right) E}{H-z}\left[1+\frac{(R-r)^{2}}{2(H-z)^{2}}\right] \mathrm{d} z .
\end{aligned}
$$

3.2. Elliptic Hypothesis and Convexity Coefficient. In practice, the compression deformation of the ring rubber pad is irregular, and many rubber pads have rubber covers glued together at both ends; therefore, it is unreasonable to assume rectangular deformation. In this study, in order to better characterize the deformation of the rubber pad, the elliptic deformation hypothesis is adopted for calculation and analysis.

Figure 6(a) shows the initial state of the annular rubber pad, Figure 6(b) shows the state based on the rectangle hypothesis, and Figure 6(c) shows the state based on the ellipse hypothesis.

When the rubber spring is compressed, the bearing area does not change because the area of the rubber cover is constant, but the free area changes, and the middle of the rubber spring expands outward. Under general pressure, there is enough expansion space inside the annular rubber pad. Two assumptions are made based on the vertical section profile in Figure 7: (a) Assume that the vertical section of the rubber pad extruded part is semiellipse. (b) Assume that the sizes of the inner and outer semiellipses are the same. In Figure 7, the center of the rubber pad is selected as the origin to establish a rectangular coordinate system; the transverse half axis of the semiellipse is represented by $a$, and the vertical half axis is represented by $b$. The analytic geometric expression of the contour curve in Figure 7 is given by

$$
\begin{aligned}
\frac{(x-R)^{2}}{a^{2}}+\frac{z^{2}}{b^{2}} & =1, \quad R \leq x \leq R+a, \\
z & = \pm b, \quad-R<x<-r \cup r<x<r, \\
\frac{(x-r)^{2}}{a^{2}}+\frac{z^{2}}{b^{2}}=1, & \quad r-a \leq x \leq r, \\
\frac{(x+r)^{2}}{a^{2}}+\frac{z^{2}}{b^{2}}=1, & -r \leq x \leq-r+a, \\
\frac{(x+R)^{2}}{a^{2}}+\frac{z^{2}}{b^{2}}=1, & -R-a \leq x \leq-R .
\end{aligned}
$$

According to the volume invariance of rubber spring, it can be calculated as follows:

$$
\begin{aligned}
V & =\pi\left(R^{2}-r^{2}\right) H=2 \int_{0}^{b} \pi\left(x_{1}^{2}-x_{2}^{2}\right) \mathrm{d} z \\
& =2 \pi b\left(R^{2}-r^{2}\right)+a b \pi(R+r) .
\end{aligned}
$$

In formula (10), $V$ represents the volume of the rubber pad, $x_{1}$ represents the coordinates of the points on the outer contour of the rubber pad, and $x_{2}$ represents the coordinates of the points on the inner contour of the rubber pad. $b$ is given by

$$
b=\frac{H-h_{\text {pre }}}{2} .
$$

By further calculation, we can get 


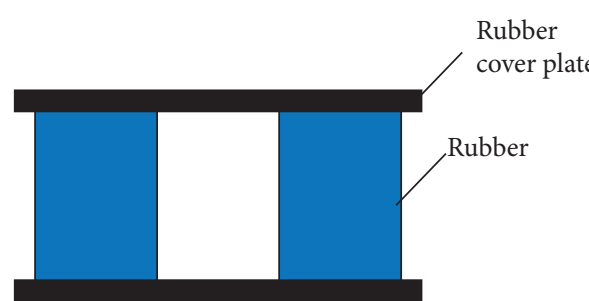

(a)

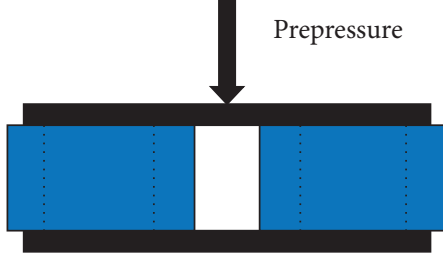

(b)

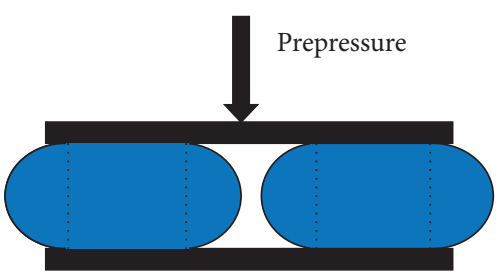

(c)

FIgURE 6: Compression deformation diagram of annular rubber pad.

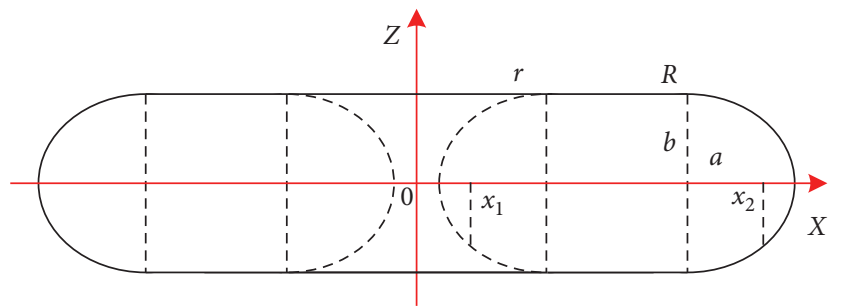

Figure 7: The vertical section profile of Figure 6(c).

$$
a=\frac{(R-r)(H-2 b)}{b}=2 \frac{(R-r) h_{\mathrm{pre}}}{H-h_{\mathrm{pre}}} .
$$

The total free area $A_{\mathrm{f} 2}$ of the rubber spring is the sum of the outer and inner sides of the ellipse; it can be calculated by

$$
A_{\mathrm{f} 2}=4 \pi \int_{0}^{b}\left(x_{1}+x_{2}\right) \mathrm{d} z=4 b \pi(R+r)=2 \pi(R+r)\left(H-h_{\mathrm{pre}}\right) .
$$

By comparison, the results of the ellipse hypothesis and rectangle hypothesis are the same for the calculation of the free area:

$$
A_{\mathrm{f} 2}=A_{\mathrm{f} 1}=2 \pi(R+r)\left(H-h_{\mathrm{pre}}\right) .
$$

The conclusion formula (14) is based on the assumption that the changes of inner and outer dimensions are equal. If this assumption is not established, then the difference between $A_{\mathrm{f} 2}$ and $A_{\mathrm{f} 1}$ is always small.

Based on the above analysis, the conclusion can be drawn: under the assumption that the internal and external expansions are equal, the static stiffness calculation formulas of the two shape assumptions are the same; if only the ellipse assumption is used, the accuracy of the static stiffness calculation cannot be improved.

In practical applications, the vertical stiffness of rubber spring increases with an increase in prepressure due to the influence in geometric and material nonlinearity. In formula (8), although shape variation and area ratio are considered, there is still a large error between the calculated value and the actual value, so maybe it is not enough to use area ratio to correct the formula. When the ellipse hypothesis is considered, it is necessary to use the degree of ellipse deformation to further modify the calculation formula (8).

In this study, the additional convexity coefficient is introduced to modify the stiffness calculation formula, which can also be understood as the modification of modulus in case of large preload; this understanding does not affect the calculation results. Convexity coefficient is a function, not a specific value. The higher the compression degree of rubber spring is, the more obvious the sides protrude inward and outward and the greater the change of rubber performances is. The effective coefficient of convexity should be able to represent these changes, so the coefficient of convexity $\mu_{\text {con }}$ is defined as

$$
\mu_{\text {con }}=1+\frac{a}{b}
$$

In this case, the stiffness $k_{\text {st2 }}$ of the rubber pad can be calculated as follows:

$$
\begin{aligned}
k_{\mathrm{st} 2} & =\frac{A_{\mathrm{c} 2} \mu_{2} E}{H-h_{\text {pre }}} \mu_{\text {con }}=\frac{\pi\left(R^{2}-r^{2}\right) E}{H-h_{\text {pre }}}\left[1+\frac{\left(R^{2}-r^{2}\right)^{2}}{8 b^{2}(R+r)^{2}}\right]\left(1+\frac{a}{b}\right) \\
& =\frac{\pi\left(R^{2}-r^{2}\right) E}{H-h_{\text {pre }}}\left[1+\frac{(R-r)^{2}}{2\left(H-h_{\text {pre }}\right)^{2}}\right]\left(1+\frac{a}{b}\right),
\end{aligned}
$$

where $A_{\mathrm{c} 2}$ represents the bearing area, $A_{\mathrm{c} 2}=A_{\mathrm{c} 1}=\pi\left(R^{2}-r^{2}\right), \mu_{2}$ is the vertical shape coefficient, and the calculation method refers to formula (6). The relationship between prepressure $F_{\text {st2 }}$ and precompression amplitude $h_{\text {pre }}$ can be given by

$F_{\text {st } 2}=\int_{0}^{h_{\text {pre }}} k_{\text {st } 2} \mathrm{~d} z=\int_{0}^{h_{\text {pre }}} \frac{\pi\left(R^{2}-r^{2}\right) E}{H-z}\left[1+\frac{(R-r)^{2}}{2(H-z)^{2}}\right]\left(1+\frac{a}{b}\right) \mathrm{d} z$.

In formula (17), $a$ and $b$ correspond to formula (12) and formula (11), respectively, and $h_{\text {pre }}$ in $a$ and $b$ is replaced by the variable $z$.

If prepressure is given instead of the precompression amplitude value, the precompression amplitude value can be calculated by using the inverse function $h_{\text {pre }}=f^{-1}\left(F_{\text {st } 2}\right)$ of the function $F_{\text {st2 }}=f\left(h_{\text {pre }}\right)$, and then calculate the stiffness according to formula (16). Due to difficulty in calculation for the inverse function, $h_{\text {pre }}$ can be obtained by computer numerical processing.

3.3. DFCC and Parameter Calculation. According to the static stiffness calculation formula (16), the static stiffness under different prepressures is different. In order to compare 
the changes of static stiffness under different prepressures, the DFCC $\lambda_{N \bullet j z}$ is defined as

$$
\lambda_{N \bullet j z}=\frac{k_{N}}{k_{j z}}=\frac{\left(1 /\left(H-h_{\mathrm{pre}}\right)\right)\left[1+\left((R-r)^{2} / 2\left(H-h_{\mathrm{pre}}\right)^{2}\right)\right](1+(a / b))}{\left(1 /\left(H-h_{j z}\right)\right)\left[1+\left((R-r)^{2} / 2\left(H-h_{j z}\right)^{2}\right)\right]\left(1+\left(a_{j z} / b_{j z}\right)\right)}
$$

where $k_{N}, h_{\text {pre }}, a$, and $b$, respectively, represent the static stiffness, precompression amplitude, ellipse horizontal half axis, and vertical half axis when the prepressure is $N$, and $k_{j z}, h_{j z}, a_{j z}$, and $b_{j z}$ are the corresponding parameters of the fiducial prepressure.

The dynamic characteristics of the rubber pad have a complex relationship with the amplitude and frequency. In order to highlight the research focus and more clearly reveal the change rule of performance parameters with the prepressure, select a specific frequency and amplitude for comparison; only consider the relative change of performance parameters when the prepressure changes. According to the assumptions that the parameters of dynamic-static parameters increase in the same proportion with the change of prepressure, and according to formula (18), the following formula can be obtained:

$$
\begin{aligned}
k_{N} & =k_{j z} \lambda_{N \bullet j z}, \\
k_{N \bullet i j} & =k_{j z \bullet i j} \lambda_{N \bullet j z}, \\
c_{N \bullet i j} & =c_{j z \bullet i j} \lambda_{N \bullet j z}, \\
W_{N \bullet i j} & =W_{j z \bullet i j} \lambda_{N \bullet j z} .
\end{aligned}
$$

In formula (19), the working conditions of performance parameters are expressed by subscripts, $i$ is frequency, $j$ is amplitude, $N$ is prepressure of the condition to be predicted, and $j z$ is fiducial prepressure.

\section{Theoretical Analyses of Model Hypotheses}

4.1. Influence Mechanism of Prepressure on the Characteristics of Rubber Spring. Rubber material has entropy elasticity and energy elasticity. The nature of high elasticity is entropy elasticity [30, 31]; owing to the hot motion of the polymer chain, the chain segment rotates around a polymer chain axis in a small range, and the conformation changes. The more convoluted the chain, the more possible conformations and the higher the entropy of the system. On the other hand, the straighter the chain, the fewer the possible conformations and the smaller the entropy of the system. This elasticity due to the thermal motion of the molecules, that is, the increase in entropy of the system, is called entropy elasticity. In the initial free state of the rubber spring, considering the effect of thermal motion, the mesh chain between the crosslinking points can be regarded as an irregular line group, and its terminal distance conforms to the Gauss distribution, with high conformational entropy. When the rubber spring is compressed, all mesh chains deform. As a result of mesh chains deformation, the order of mesh chains is improved, and the conformational entropy of rubber spring is decreased. According to the entropy increase theory, the rubber spring produces a rebound force.

In the actual rubber deformation, the extension of the molecular chain will also cause some changes in bond length, bond angle, and intermolecular interaction, resulting in the change of energy in the system. Changes in internal energy also affect the elastic force, which is the elastic energy; the strain energy density function is commonly used to describe the elasticity of rubber $[32,33]$. When the deformation is small, the contribution of energy elasticity to elastic force is obvious, while when the deformation is large, entropy elasticity dominates.

The stiffness of the rubber spring increases with an increase in the prepressure due to geometric nonlinearity and material nonlinearity. When the rubber element is compressed, the molecular chain tends to be more transverse, and the increase of the ordered chain helps the adjacent mesh chains to bind together, thus playing an additional crosslinking role. The increase in the crosslinking degree will lead to the increase of modulus and stiffness, which will eventually lead to the increase in compression stiffness of rubber. In addition, with the increase in the compression amount, the molecular chains of the rubber spring become less and less curly, and the lateral elongation becomes more and more difficult, so more and more pressure is needed to produce the same compression displacement; that is, the stiffness of the rubber spring in the precompression position becomes larger and larger.

\subsection{Theoretical Analysis of Stiffness Variation Rule Hypothesis.} Whether on dynamic or static conditions, when the prepressure is the same, the shape variable of the rubber spring in the balance position is the same. In other words, the transverse elongation of rubber spring molecular chain is the same, so it can be considered that the influences of prepressure on static stiffness and dynamic stiffness are similar. If the stress relaxation of rubber spring is simply described by Maxwell model, the following formula can be obtained:

$$
E(t)=E e^{(-t / \tau)}
$$

where $E(t)$ is the stress relaxation modulus at $t$ and $\tau$ is the time constant.

In fact, the static state is a quasi-static state with very low frequency, so, at any displacement, it can be considered that the rubber has a long time to relax, and the dynamic state has less time to relax at any position. 
If very small displacement range $\Delta x$ is considered as a point for calculation, assuming that the relaxation time of static condition at each point is $t_{1}$ and the relaxation time of dynamic condition at each point is $t_{2}$, then $t_{1}>t_{2}$ is always true if the amplitudes are the same:

$$
\begin{aligned}
& E\left(t_{1}\right)=E e^{\left(-t_{1} / \tau\right)}<E\left(t_{2}\right)=E e^{\left(-t_{2} / \tau\right)}, \\
& \frac{E\left(t_{2}\right)}{E\left(t_{1}\right)}=e^{\left(\left(-t_{2}+t_{1}\right) / \tau\right)}>1 .
\end{aligned}
$$

According to formulas (16), (17), and (21), we can get

$$
k_{\mathrm{d}}=e^{\left(\left(-t_{2}+t_{1}\right) / \tau\right)} k_{\text {st }} \text {. }
$$

From formula (22), when the amplitude is the same, the dynamic stiffness $k_{\mathrm{d}}$ equals the static stiffness $k_{\text {st }}$ times the frequency-dependent coefficient $e^{\left(\left(-t_{2}+t_{1}\right) / \tau\right)}$. When only the prepressures change, it is considered that $e^{\left(\left(-t_{2}+t_{1}\right) / \tau\right)}$ is a fixed value, the dynamic and static stiffness change laws are similar, and the dynamic stiffness is greater than the static stiffness.

Based on the above analysis, when only the prepressures change, it is reasonable to assume that dynamic stiffness and static stiffness have the same change proportion.

\subsection{Theoretical Analysis of Dynamic Parameter Variation} Rule Hypothesis. For dynamic conditions with the same frequency and amplitude, the equivalent stiffness of rubber springs is different under different prepressure. The greater the prepressure, the greater the equivalent stiffness, as shown in Figure 5(a). In Figure 8, the precompression position is set to the displacement 0 point, $F_{N \max }$ is the spring force corresponding to the maximum displacement when the preload is $N, F_{j z \max }$ is the spring force corresponding to the maximum displacement when the preload is fiducial prepressure $N_{j z}$, and $k_{N}$ and $k_{j z}$ are the corresponding equivalent stiffnesses. The DFCC $\lambda_{N \bullet j z}$ can be calculated as follows:

$$
\lambda_{N \bullet j z}=\frac{k_{N}}{k_{j z}}=\frac{F_{N \text { max }} / x_{0}}{F_{j z \max } / x_{0}}=\frac{F_{N \max }}{F_{j z \max }} .
$$

In an ideal case, considering the same displacement point (distinguishing compression and rebound travel), $F_{N}=\lambda_{N \bullet j z} F_{j z}$ holds. According to the calculation formula $W=\int F \mathrm{~d} x$ of periodic energy consumption, we can get

$$
\frac{W_{N}}{W_{j z}}=\frac{\int F_{N} \mathrm{~d} x}{\int F_{j z} \mathrm{~d} x}=\frac{\int \lambda_{N \bullet j z} F_{j z} \mathrm{~d} x}{\int F_{j z} \mathrm{~d} x}=\lambda_{N \bullet j z} .
$$

The following formula can be obtained by combining formulas (2) and (24):

$$
c_{N}=\lambda_{N \bullet j z} c_{j z}
$$

According to the above analysis, it can be seen that, in the case of the same dynamic frequency and amplitude, with only the change of prepressure, the increases in dynamic equivalent stiffness and equivalent damping are similar, so,

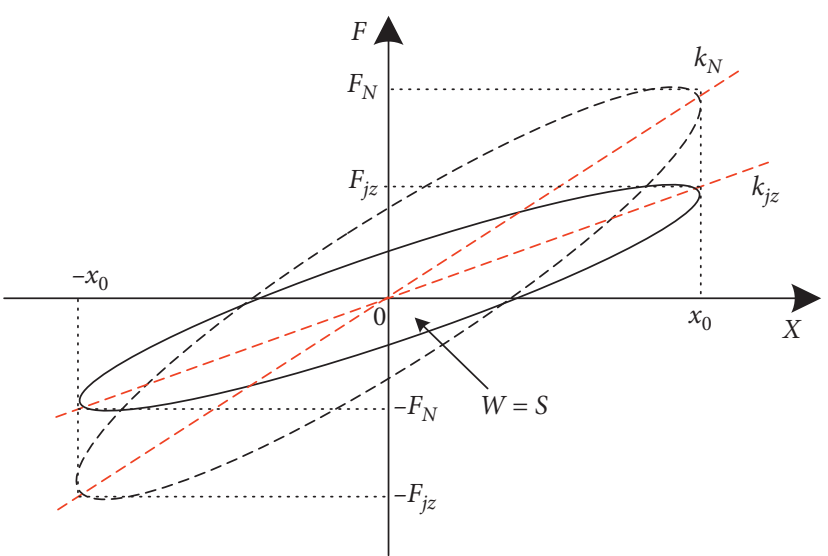

FIGURE 8: Dynamic hysteresis curve under different prepressures.

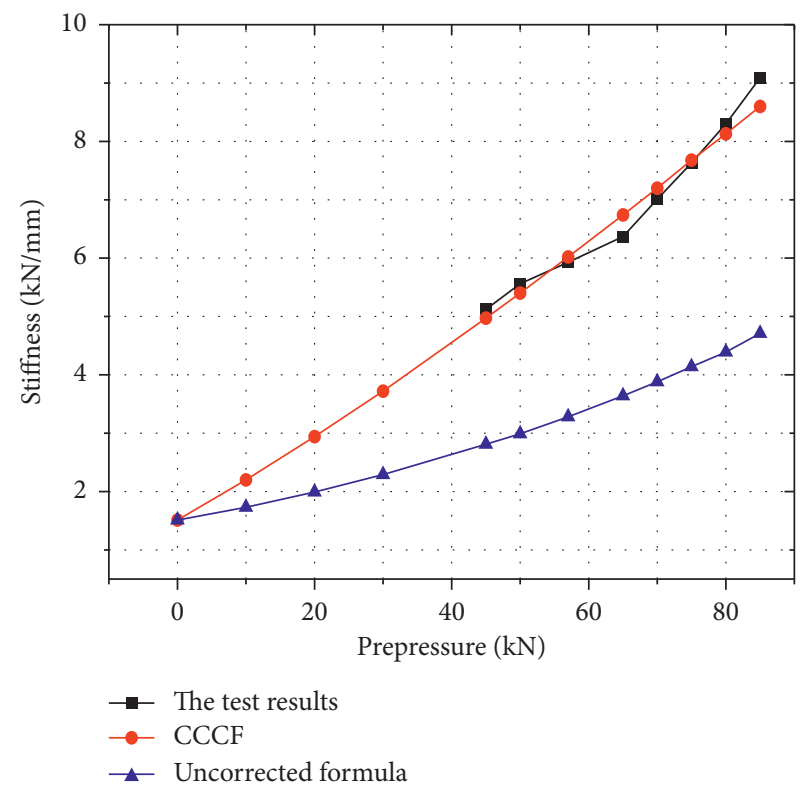

Figure 9: Comparison curves of different models.

theoretically, if only the prepressures change, it is reasonable to assume that the damping coefficient and dynamic stiffness have the same change proportion.

\section{Test Analysis of the Calculation Model}

5.1. Error Analysis of the CCCF. For the analysis of the validity of the modified formula, the CCCF, unmodified formula, and experimental data were compared to analyze the calculation errors. Figure 9 shows the results.

From Figure 9, it can be seen that CCCF is very close to the test results, and the maximum error of CCCF in the commonly used prepressure range (according to the train load) is within 6\%; the unmodified rectangular approximate calculation method is almost about $50 \%$; only in the case of very small prepressure, the two calculation methods are relatively close. Based on the comparative analysis, CCCF is more accurate to calculate the static stiffness of rubber pad, 
TABLE 1: Theoretical and experimental comparison of A and B stiffness.

\begin{tabular}{|c|c|c|c|c|c|}
\hline & \multirow{2}{*}{ Basic parameters } & \multirow{2}{*}{ Prepressure $(\mathrm{kN})$} & \multicolumn{3}{|c|}{ Static stiffness $(\mathrm{kN} / \mathrm{mm})$} \\
\hline & & & Test results & $\mathrm{CCCF}$ & Unmodified formula \\
\hline A & $\begin{array}{l}R=113 \mathrm{~mm} ; r=40.5 \mathrm{~mm} \\
H=20.5 \mathrm{~mm} ; E=2.28 \mathrm{MPa}\end{array}$ & 34 & 49.68 & 52.25 & 32.88 \\
\hline B & $\begin{array}{l}R=102 \mathrm{~mm} ; r=40.5 \mathrm{~mm} \\
H=22 \mathrm{~mm} ; E=2.28 \mathrm{MPa}\end{array}$ & 34 & 32.40 & 32.12 & 18.28 \\
\hline
\end{tabular}
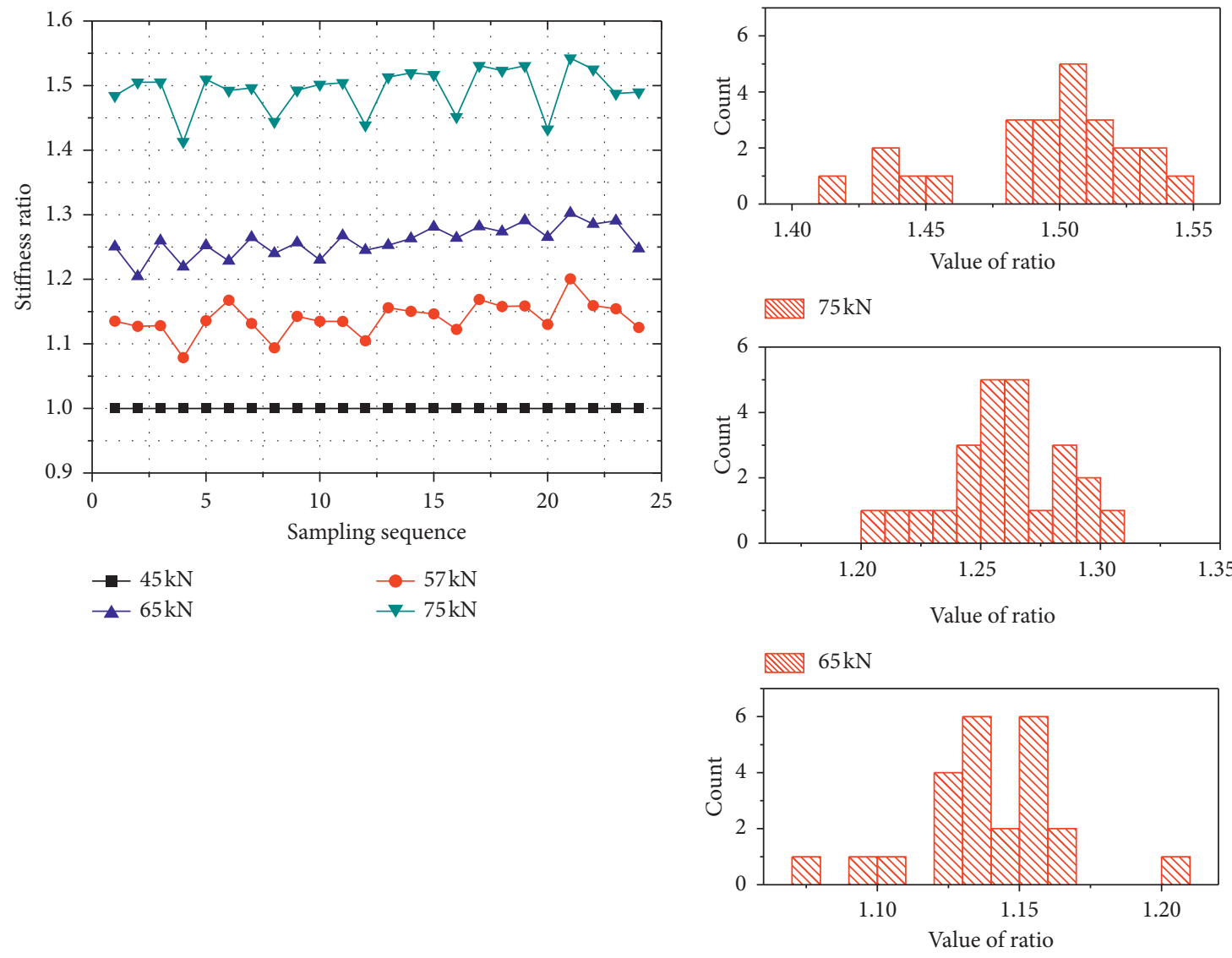

$57 \mathrm{kN}$

(a)

(b)

Figure 10: The curve of the stiffness ratio and interval statistics. (a) The curve of the stiffness ratio. (b) Chart of frequency distribution.

and the error is greatly reduced compared with the original calculation method.

In order to further verify the accuracy of CCCF calculation, annular rubber pads $\mathrm{A}$ and $\mathrm{B}$ of a metro train are selected for static stiffness analysis. The results show that the formula is still very accurate. As shown in Table 1, the calculation errors of CCCF are only $5.17 \%$ and $0.62 \%$. Therefore, CCCF may be universal to the annular rubber pad, and its better calculation accuracy is not an accidental phenomenon, which can reflect some basic physical laws of the rubber pad after compression.

5.2. Test Verification of DFCC. According to the test data, $k_{i j}$, $W_{i j}$, and $c_{i j}$ of $45 \mathrm{kN}$ prepressure were selected as the calculation bases, and these parameters are expressed as $k_{45 i j}, W_{45 i j}$, and $c_{45 i j}$. According to formula (2), for specific frequency and amplitude, the difference between $W_{45 i j}$ and $c_{45 i j}$ is a fixed scale factor $\left(1 /\left(\pi \omega x_{0}^{2}\right)\right)$, and the result after conversion is exactly the same, so the conversion of $W_{45 i j}$ will not be discussed in detail. $\eta_{i j}$ is less sensitive to the change of prepressure and will not be discussed here. Owing to the problems such as equipment error in the test, too small dynamic amplitude, too high frequency, and prepressure force may cause irregular jump of measurement data. The fiducial prepressure was selected as $45 \mathrm{kN}$ to calculate the DFCC under different working conditions, with the frequency of $0.5 \mathrm{~Hz}, 1 \mathrm{~Hz}, 2 \mathrm{~Hz}, 5 \mathrm{~Hz}, 7 \mathrm{~Hz}$, and $10 \mathrm{~Hz}$, the amplitude of $0.5 \mathrm{~mm}, 1 \mathrm{~mm}, 1.5 \mathrm{~mm}$, and $2 \mathrm{~mm}$, and the prepressure of $45 \mathrm{kN}, 57 \mathrm{kN}, 65 \mathrm{kN}$, and $75 \mathrm{kN}$. 

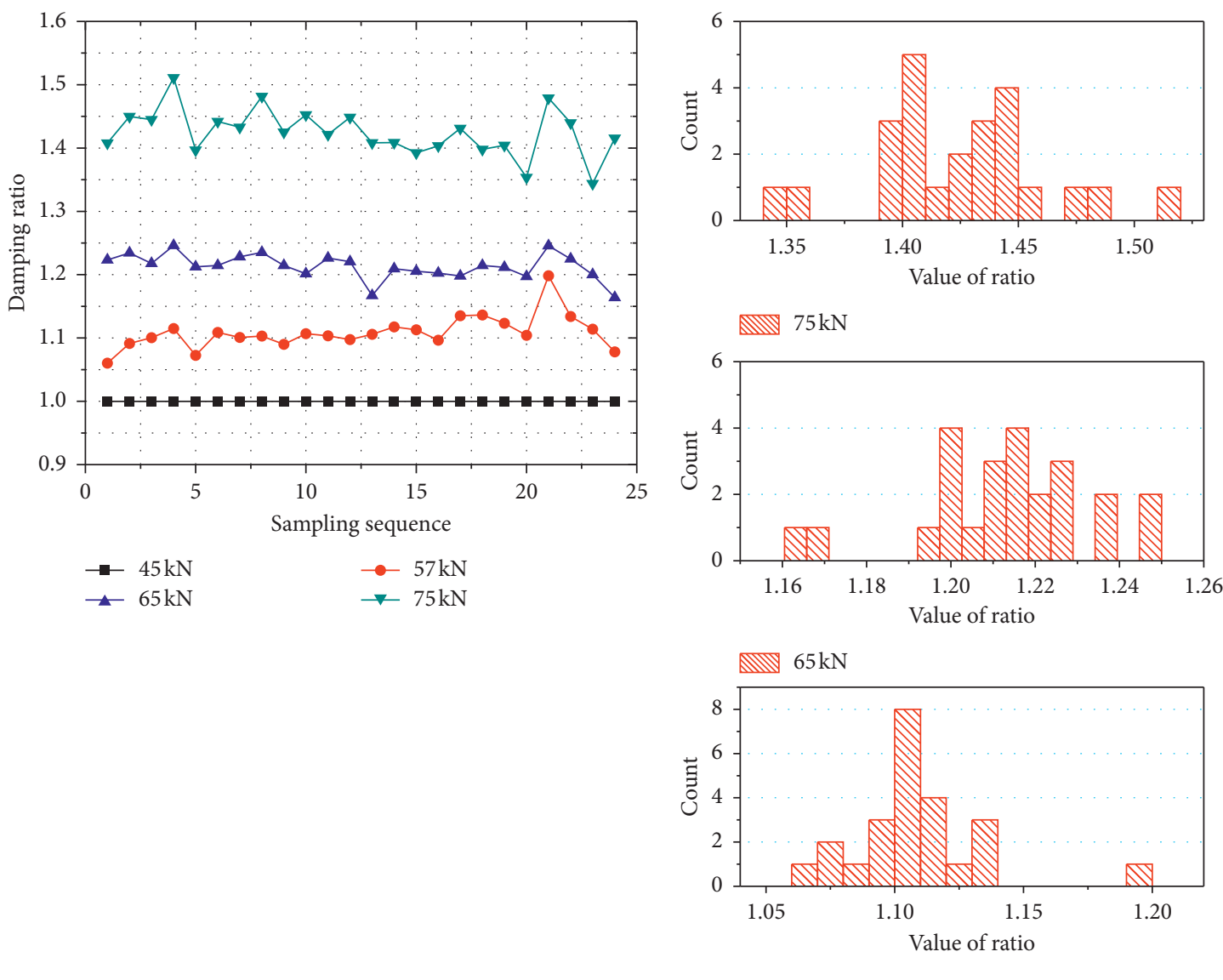

$57 \mathrm{kN}$

(a)

(b)

FIgURE 11: The curve of the damping ratio and interval statistics. (a) The curve of the damping ratio. (b) Chart of frequency distribution.

Taking the different combinations of frequency and amplitude as sample points, there are 24 samples in total, and each sample has 4 state DFCC values. Figures 10 and 11 are given based on the DFCC calculation results: Figure 10 shows the DFCC of dynamic stiffness and Figure 11 shows the DFCC of damping coefficients.

It can be seen from Figures 10 and 11 that, regardless of the combination of frequency and dynamic amplitude, the conversion coefficient under the same prepressure is obviously stable in a small fixed range. Therefore, it can be considered that the prepressure has a significant effect on the DFCC of stiffness and damping coefficient, and the degrees of influence for different combination sequences of frequency and amplitude are similar. In the frequency and amplitude range of the test, the effect of frequency and amplitude on DFCC is not significant. To further analyze the influence of prepressure on dynamic performance, the arithmetic mean values of DFCC at different sampling points are calculated under the same preload, as shown in Table 2.

According to the analysis of Table 2, under the same prepressure, the average DFCC of dynamic stiffness, periodic energy consumption, damping coefficient, and static stiffness is very close, and the maximum relative difference is
TABLE 2: Arithmetic mean of DFCC under different prepressures.

\begin{tabular}{lcccc}
\hline & $45 \mathrm{kN}$ & $57 \mathrm{kN}$ & $65 \mathrm{kN}$ & $75 \mathrm{kN}$ \\
\hline Average DFCC of $k_{i j}$ & 1 & 1.139 & 1.259 & 1.493 \\
Average DFCC of $W_{i j}$ & 1 & 1.109 & 1.213 & 1.424 \\
Average DFCC of $c_{i j}$ & 1 & 1.109 & 1.213 & 1.424 \\
Average DFCC of $k_{\text {st }}$ & 1 & 1.123 & 1.227 & 1.460 \\
\hline
\end{tabular}

only 2.61\%. The mean DFCC under each preload contains 24 combinations of frequency and amplitude, which may not be accidental. The high approximation of DFCC may reflect some deep relationship; that is to say, the influence trend and degree of prepressure on dynamic stiffness, periodic energy consumption, damping coefficient, and static stiffness are similar, with similar quantitative relationship.

Through the above test analysis, it can be concluded that the assumption that the dynamic and static parameters change in the same proportion is in line with the actual test, and it is feasible to use DFCC with static stiffness to calculate the dynamic characteristics under different prepressures. It is complex and difficult to calculate the dynamic characteristics directly by using the foundation parameters; the calculation of dynamic characteristics is affected by many factors, such as 


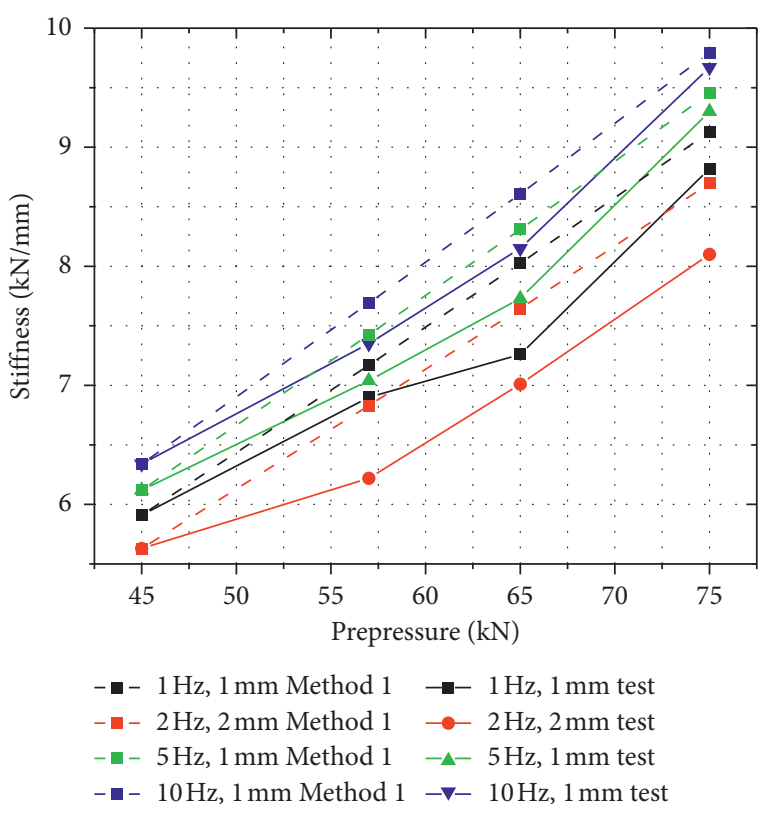

(a)

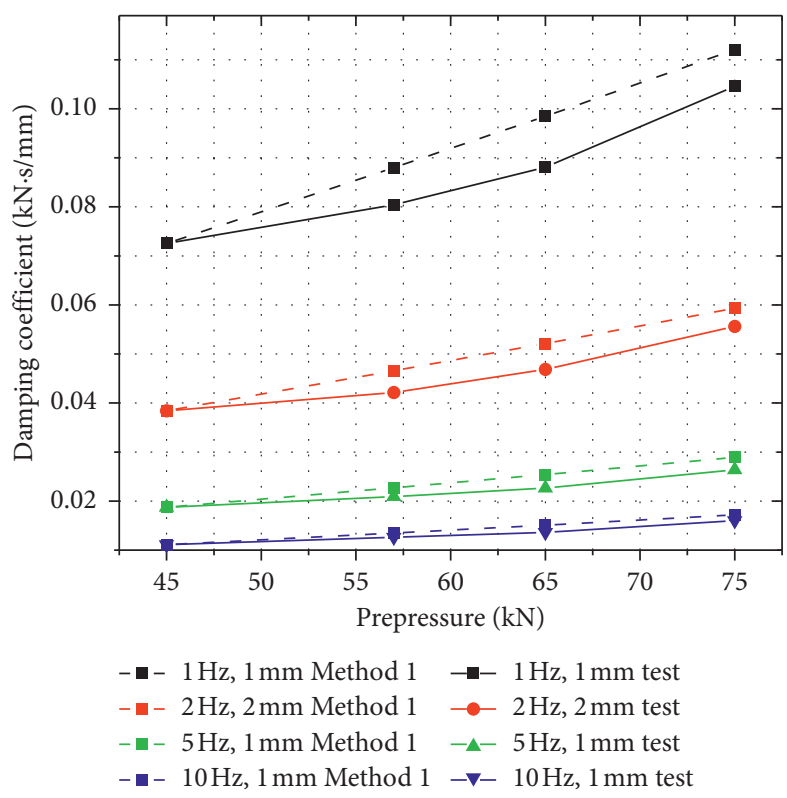

(b)

Figure 12: Comparison between Method 1 and test value.

geometric size, modulus, frequency, amplitude, prepressure, temperature, and humidity. Therefore, in this study, based on the dynamic parameters of a certain prepressure, the dynamic parameters under different prepressures are calculated by DFCC, which is very meaningful for the prediction of dynamic performances of trains under different loads.

5.3. Error Analysis of the DFCC Method. Select $45 \mathrm{kN}$ as the conversion standard, and calculate $\lambda_{\mathrm{N} \cdot 45}$ when the prepressure is $57 \mathrm{kN}, 65 \mathrm{kN}, 75 \mathrm{kN}$, and $85 \mathrm{kN}$ according to the theoretical formula (18); use formula (19) to calculate the dynamic parameters and compare with the test value, as shown in Figure 12. This method is named the theoretical DFCC prediction method (Method 1).

Select $45 \mathrm{kN}$ as the conversion standard; according to the test data and formula (1), the static stiffness $k_{\mathrm{st}}$ under different prepressures is calculated, and the ratio of test stiffness is further calculated to obtain $\lambda_{N \bullet 45}$; refer to Table 2; use formula (19) to calculate the dynamic parameters and compare with the test value, as shown in Figure 13. This method is named the test DFCC prediction method (Method 2).

As shown in Figure 12(a), the dynamic stiffness obtained by Method 1 is compared with the test value, the maximum error is $10.53 \%$, the average error is $5.85 \%$, and the root mean square error is $6.54 \%$. As shown in Figure 12(a), the dynamic damping coefficient obtained by Method 1 is compared with the test value, the maximum error is $12.26 \%$, the average error is $9.36 \%$, and the root mean square error is $9.56 \%$.
As shown in Figure 13(a), the dynamic stiffness obtained by Method 2 is compared with the test value, the maximum error is $4.85 \%$, the average error is $0.05 \%$, and the root mean square error is $2.25 \%$. As shown in Figure 13(a), the dynamic damping coefficient obtained by Method 2 is compared with the test value, the maximum error is $5.82 \%$, the average error is $3.37 \%$, and the root mean square error is $3.61 \%$.

In summary, Method 1 and Method 2 have high accuracy in fitting dynamic stiffness and damping coefficient under different prepressures. In particular, the predicted value of Method 2 is almost consistent with the actual test results. Therefore, when the prepressure is the same, the DFCC of static stiffness is similar to the DFCC of dynamic parameters. Some assumptions about DFCC are reasonable, and it is effective to use the conversion coefficient of static stiffness to describe the dynamic parameters. Both Method 1 and Method 2 can be used successfully to describe rubber pad dynamic characteristics. Method 2 has a better approximation degree due to the use of static test values, but more data of static test is needed. Although Method 1 is not as accurate as Method 2, it does not need static test data and can be directly calculated according to basic state and geometric parameters. Method 1 is more convenient and fully meets the requirements of engineering calculation. The method of DFCC is particularly important for the calculation of the dynamic performances of the rubber pad. By using this method in different prepressure conditions, only the parameters of the fiducial prepressure conditions need to be tested. The parameters of other prepressure conditions can be calculated, and this could significantly reduce the test workload. 


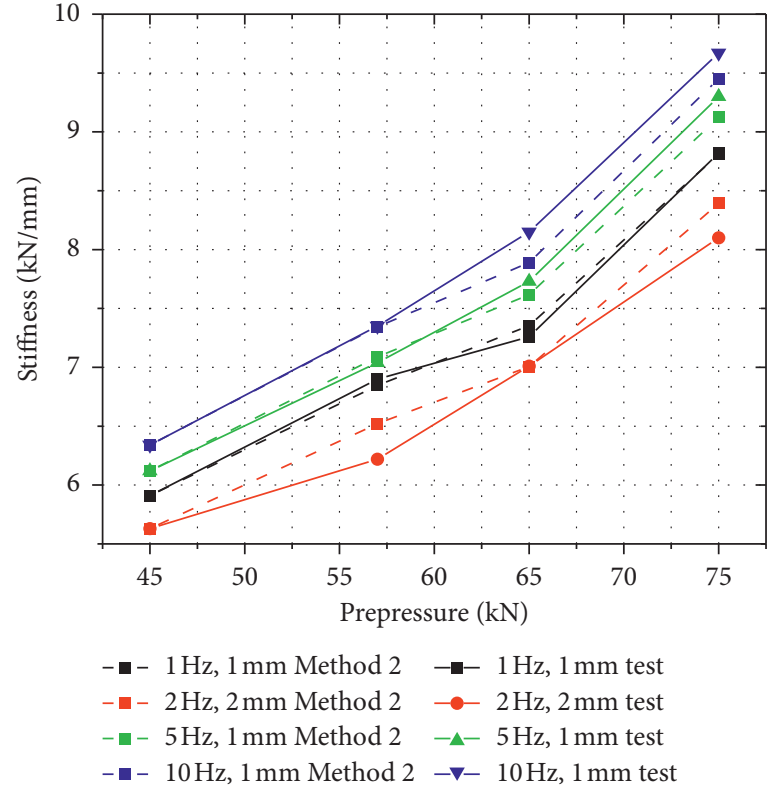

(a)

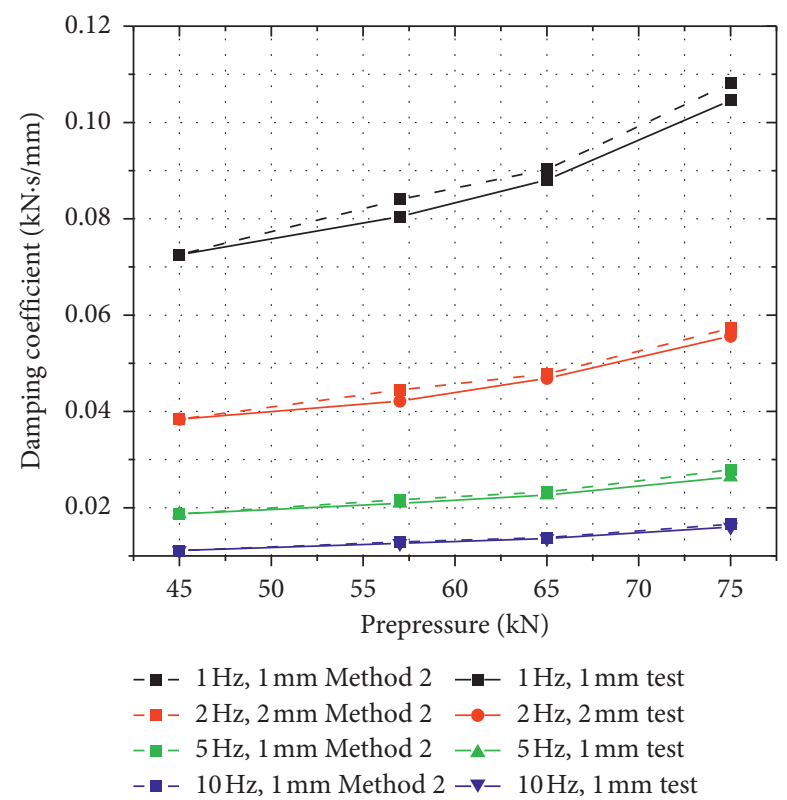

(b)

FIgURE 13: Comparison between Method 2 and test value.

\section{Conclusions}

In this study, through theoretical analysis, CCCF for static stiffness calculation is proposed, and DFCC method based on the change of prepressure is further proposed. Through the theoretical analysis and experimental verification of CCCF and DFCC, the following conclusions can be drawn:

(1) The change of the prepressure has a significant effect on the dynamic-static stiffness and damping coefficient of the rubber pad but not on the loss factor. The different combinations of dynamic frequency and amplitude do not change the influence of prepressure on dynamic characteristics.

(2) CCCF is reasonable and effective in the calculation of static stiffness, which greatly improves the calculation accuracy compared with the rectangular approximation in common use. The error within the range of common prepressure meets the engineering requirements. CCCF does not depend on test data and can be calculated directly from the basic data of rubber pad, which has a certain engineering significance.

(3) When the prepressure changes, the DFCC of static stiffness, dynamic stiffness, periodic energy consumption, and damping coefficient have very similar change laws, which is established in theory and practice. Test DFCC method is more effective than theoretical DFCC method, but theoretical DFCC method is more convenient in calculation and application.

DFCC method is effective for the calculation and prediction of rubber pad, but the applicability of other rubber components needs further study. In addition, the quantitative relationship among dynamic characteristic parameters, frequency and amplitude, still needs to be further studied in order to avoid considering different frequencies and amplitudes in the dynamic fiducial prepressure test in the current model.

\section{Data Availability}

The data used to support the findings of this study are available from the corresponding author upon request.

\section{Conflicts of Interest}

The authors declare that they have no conflicts of interest.

\section{Acknowledgments}

This research was supported by the National Key R\&D Program of China (Grant nos. 2016YFB120404 and 2018YFB1201700) and by the Independent Subject of State Key Laboratory of Traction Power (Grant no. 2018TPL_T04).

\section{References}

[1] G. M. Giovanni, E. Mele, G. Marrazzo, G. Brandonisio, and A. d. Luca, "Stability issues and pressure-shear interaction in elastomeric bearings: the primary role of the secondary shape factor," Bulletin of Earthquake Engineering, vol. 14, no. 2, pp. 569-597, 2016.

[2] L. Nasdala, A. Kempe, and R. Rolfes, "An elastic molecular model for rubber inelasticity," Computational Materials Science, vol. 106, pp. 83-99, 2015.

[3] M. Gajewski, R. Szczerba, and S. Jemioło, "Modelling of elastomeric bearings with application of yeoh hyperelastic 
material model," Procedia Engineering, vol. 111, pp. 220-227, 2015.

[4] P. Wagner, P. Wriggers, C. Klapproth, C. Prange, and B. Wies, "Multiscale FEM approach for hysteresis friction of rubber on rough surfaces," Computer Methods in Applied Mechanics and Engineering, vol. 296, pp. 150-168, 2015.

[5] O. P. Singh, T. Sreenivasulu, and M. Kannan, "The effect of rubber dampers on engine's NVH and thermal performance," Applied Acoustics, vol. 75, pp. 17-26, 2014.

[6] C. Li, G. T. Yang, and Z. Z. Huang, "Constitutive equations of incompressible nonlinear super-elastic material," Transaction of Beijing Institute of Technology, vol. 31, no. 1, pp. 30-34, 2011, Chinese.

[7] Y. Q. Li and X.-L. Gao, "Constitutive equations for hyperelastic materials based on the upper triangular decomposition of the deformation gradient," Mathematics and Mechanics of Solids, vol. 24, no. 6, pp. 1785-1799, 2019.

[8] R. Luo, H. L. Shi, J. Y. Guo, L. Huang, and J. Wang, “A nonlinear rubber spring model for the dynamics simulation of a high speed train," Vehicle System Dynamics, pp. 1-8, 2019.

[9] D. W. Zhang and S. Y. Zhu, "A fractional derivative model for rubber spring of primary suspension in railway vehicle dynamics," ASCE-ASME Journal of Risk and Uncertainty in Engineering Systems, Part B: Mechanical Engineering, vol. 3, no. 3, 2017.

[10] H. Shi and P. Wu, "A nonlinear rubber spring model containing fractional derivatives for use in railroad vehicle dynamic analysis," Proceedings of the Institution of Mechanical Engineers, Part F: Journal of Rail and Rapid Transit, vol. 230, no. 7, pp. 1745-1759, 2016.

[11] D.-w. Sun, Z.-g. Chen, G.-y. Zhang, and P. Eberhard, "Modeling and parameter identification of amplitude- and frequency-dependent rubber isolator," Journal of Central South University, vol. 18, no. 3, pp. 672-678, 2011.

[12] J. Wu and W. B. Shangguan, "Modeling and applications of dynamic characteristics for rubber isolators using viscoelastic fractional derivative model," Engineering Mechanics, vol. 25, no. 1, pp. 161-166, 2008, Chinese.

[13] P. Spanos, "Cure system effect on low temperature dynamic shear modulus of natural rubber," Rubber World, vol. 229, no. 2, pp. 22-27, 2003.

[14] M. Sjöberg and L. Kari, "Nonlinear isolator dynamics at finite deformations: an effective hyperelastic, fractional derivative, generalized friction model," Nonlinear Dynamics, vol. 33, no. 3, pp. 323-336, 2003.

[15] M. Sjöberg and L. Kari, "Non-linear behavior of a rubber isolator system using fractional derivatives," Vehicle System Dynamics, vol. 37, no. 3, pp. 17-236, 2002.

[16] M. Sjöberg, "Rubber isolators-measurements and modeling using fractional derivatives and friction," SAE Technical $\mathrm{Pa}$ pers, vol. 3518, pp. 2000-2001, 2000.

[17] Z.-L. Li, Z.-q. Liu, D.-G. Sun, B.-J. Yan, and J. Meng, "Fractional Maxwell model of viscoelastic oscillator and its frequency response," Journal of Vibration Engineering \& Technologies, vol. 6, no. 1, pp. 1-6, 2018.

[18] T. L. Yu, D. Y. Yuan, and X. L. Sun, “The finished product of rubber bearing mechanical performance analysis in the low temperature," Applied Mechanics and Materials, vol. 178-181, pp. 2254-2259, 2012.

[19] W. Teng, F. Tan, and H. Shi, "Experimental study of high/low temperature effects on the dynamic performance of rubber spring for railway vehicles," Journal of Physics: Conference Series, vol. 1213, no. 5, Article ID 052042, 2019.
[20] R. Österlöf, L. Kari, and H. Wentzel, "Temperature dependency of a viscoplastic constitutive model for rubber with reinforcing fillers," in Proceedings of the 9th European Conference on Constitutive Models for Rubbers, pp. 149-156, ECCMR, Nantes, France, July 2015.

[21] A. Stevenson, "The influence of low-temperature crystallization on the tensile elastic modulus of natural rubber," Journal of Polymer Science: Polymer Physics Edition, vol. 21, no. 4, pp. 553-572, 1983.

[22] A. Stevenson, "Effect of elastic strain on the low temperature crystallization of rubber," Plastics \& Rubber Institute, vol. 6, pp. 1-6, 1987.

[23] L. Kari, "The non-linear temperature dependent stiffness of precompressed rubber cylinders," KGK-kautschuk Gummi Kunststoffe, vol. 55, no. 3, pp. 76-81, 2002.

[24] L. Kari, "An analytical temperature-dependent collocation model for preloaded rubber cylinders," The Journal of Strain Analysis for Engineering Design, vol. 37, no. 4, pp. 289-299, 2002.

[25] Z. Y. Cheng, Z. D. Hu, and L. Li, "Study on the performance of lead rubber bearing considering vertical force correlation," International Journal of Multiphysics, vol. 12, no. 3, pp. 267-282, 2018.

[26] C. G. Koh and J. M. Kelly, "A simple mechanical model for elastomeric bearings used in base isolation," International Journal of Mechanical Sciences, vol. 30, no. 12, pp. 933-943, 1988.

[27] K. L. Ryan, J. M. Kelly, and A. K. Chopra, "Nonlinear model for lead-rubber bearings including axial-load effects," Journal of Engineering Mechanics, vol. 131, no. 12, pp. 1270-1278, 2005.

[28] D. Foti, A. Catalan Goni, and S. Vacca, "On the dynamic response of rolling base isolation systems," Structural Control and Health Monitoring, vol. 20, no. 4, pp. 639-648, 2013.

[29] N. Menga, D. Foti, and G. Carbone, "Viscoelastic frictional properties of rubber-layer roller bearings (RLRB) seismic isolators," Meccanica, vol. 52, no. 11-12, pp. 2807-2817, 2017.

[30] P. S. He, P. P. Zhu, and H. Yang, "Characteristics of rubber elasticity,” Polymer Bulletin, vol. 12, pp. 68-71, 2009, in Chinese.

[31] E. M. Arruda and M. C. Boyce, "A three-dimensional constitutive model for the large stretch behavior of rubber elastic materials," Journal of the Mechanics and Physics of Solids, vol. 41, no. 2, pp. 389-412, 1993.

[32] R. W. Ogden, "Recent advances in the phenomenological theory of rubber elasticity," Rubber Chemistry and Technology, vol. 59, no. 3, pp. 361-383, 1986.

[33] M. Mooney, "A theory of large elastic deformation," Journal of Applied Physics, vol. 11, no. 9, pp. 582-592, 1940. 